\title{
Formação de professores/as em gênero e sexualidade: possibilidades e desafios ${ }^{1}$
}

\section{Teacher training in gender and sexuality: opportunities and challenges}

\author{
Zilene Pereira Soares* \\ Simone Souza Monteiro**
}

\begin{abstract}
RESUMO
A pesquisa analisou a influência do curso Gênero e Diversidade na Escola (GDE) sobre a abordagem das temáticas gênero e sexualidade na prática pedagógica de 12 professores/as de Ciências do Ensino Fundamental no Estado do Rio de Janeiro. A pesquisa foi orientada por uma abordagem qualitativa, e a partir de entrevistas semiestruturadas constatou-se que o curso contribuiu para ampliar a visão dos/as docentes acerca da construção sociocultural das identidades sexuais e de gênero, e subsidiou a implementação de atividades sobre o tema no contexto escolar. Os depoimentos assinalaram para a necessidade de formação continuada de profissionais da educação e de iniciativas de consolidação das ações dentro das instituições escolares. Revelaram as difíceis condições de trabalho, falta de incentivos e entraves diversos que aumentam o sentimento de isolamento entre esses profissionais que lutam por modificar uma realidade. Contudo, pequenas iniciativas, ainda que em diferentes intensidades, trazem contribuições importantes ao cotidiano, apontando para o início da construção de uma sociedade mais justa e igualitária. Conclui-se que inserir o tema em sala de aula depende quase que exclusivamente da disposição pessoal do/a professor/a em enfrentar todas as adversidades na afirmação dos direitos de igualdade. Espera-se que esse trabalho possa contribuir para a transformação das práticas escolares, desestabilizando padrões pré-concebidos, além de ampliar a divulgação de pesquisas na área de Ensino de Ciências.
\end{abstract}

Palavras-chave: Sexualidade. Gênero. Ensino de Ciências.

1 Agência de financiamento da Coordenação de Aperfeiçoamento de Pessoal de Nível Superior (CAPES).

* Universidade Federal de Goiás. Instituto de Ciências Biológicas. E-mail: zilenemor@gmail.com. https://orcid.org/0000-003-0166-9235.

** Fundação Oswaldo Cruz. Instituto Oswaldo Cruz. E-mail: monteiro.simone.fiocruz@ gmail.com . https://orcid.org/0000.0003.2009.1790. 


\begin{abstract}
The research analyzed the influence of the Gender and Diversity Course at School (GDS) on the approach of gender and sexuality themes in the pedagogical practice of 12 Sciences teacher of Elementary Education in Rio de Janeiro State, Brazil. The research was guided by a qualitative approach and from semi-structured interviews. It was found that the course contributed to broaden the view of teachers on the socio-cultural construction of sexual and gender identities and subsidized the implementation of activities on the subject in the school context. The testimonies pointed to the need for continuing education to professionals who work with education subjects and more initiatives to consolidate actions within school institutions. Those testimonies revealed difficult working conditions, lack of incentives and various obstacles that increase the feeling of isolation among these professionals who struggle to change a reality. However, small initiatives, even in different intensities, bring important contributions to daily life pointing to the beginning of the construction of a more fair and egalitarian society. It is concluded that inserting the theme in the classroom depends almost exclusively on the teacher's personal disposition to face all adversities in affirming the rights of equality. It is hoped that this work may contribute to the transformation of school practices, destabilizing pre-conceived patterns as well as expanding the dissemination of research in the area of Science Teaching.
\end{abstract}

Keywords: Sexuality. Gender. Science Education.

\title{
Introdução
}

O debate em torno de questões envolvendo sexualidade e gênero vem ganhando cada vez mais espaço nos diversos âmbitos sociais, conjugando-se até mesmo com a luta pelos direitos humanos e pela democracia no país. A todo instante diferentes discursos se contrapõem, configurando-se num quadro de avanços e recuos na luta pela igualdade no Brasil. Os exemplos das conquistas no campo da sexualidade e gênero são numerosos, dentre eles estão: a aprovação pelo STF (Supremo Tribunal Federal) que transexuais e transgêneros possam mudar o nome no registro civil sem a necessidade de cirurgias; as conquistas de títulos acadêmicos e postos de trabalho por pessoas transexuais e travestis, manchete constante nas mídias; a inserção dessa discussão em livros didáticos, obras literárias e avaliações para ingresso nas universidades; o protagonismo de mulheres jovens durante o movimento de ocupações nas escolas de todo Brasil, problematizando a participação política e as desigualdades de gênero 
(MIRANDA; SANTOS, 2017); ampliação da legislação acerca da violência de gênero, etc. Entretanto, em contraposição a isso se observa uma série de iniciativas que restringem os direitos, principalmente de mulheres e pessoas trans, a saber: a aprovação em novembro de 2017 da Proposta de Emenda à Constituição 181 (PEC 181) ${ }^{2}$, que ameaça os direitos sexuais e reprodutivos das mulheres; o número crescente de casos de violência contra mulher e contra a população LGBTTI (lésbicas, gays, bissexuais, travestis, transexuais e intersexos); os diversos casos de censura aos museus ocorridos nos últimos anos; no âmbito da educação embora o Projeto Escola sem Partido tenha sido arquivado no Senado, ainda persiste uma série de Projetos de Lei que tramitam no Congresso Federal, Estados e Municípios que compartilham os ideais desse movimento (MOURA, 2016); restrições à abordagem da diversidade sexual e de gênero com os formulários extrajudiciais contra a chamada "ideologia de gênero" nas escolas, a Reforma do Ensino Médio, que altera a Lei de Diretrizes e Bases da Educação Nacional (LDB), a nova Base Nacional Comum Curricular (BNCC), e o Plano Nacional de Educação (PNE), este último que retirou toda e qualquer menção à palavra gênero.

Diante do quadro exposto se confirma o deslocamento que questões envolvendo sexualidade e gênero vêm sofrendo, que as tornam centrais na luta pela democracia no Brasil (SEFFNER; BORRILLO; RIBEIRO, 2018). Considerando a escola como um dos principais espaços de socialização para crianças, jovens e adultos destaca-se que para alcançar os ideais democráticos e de direito é necessário que a discussão envolvendo a diversidade sexual e de gênero esteja presente no dia a dia escolar. A retirada dos temas gênero e orientação sexual do PNE e da BNCC tira a legitimidade do tema, entretanto isso não significa que professores/as não possam abordá-los, tendo em conta que fazem parte das demandas dos próprios estudantes. Além disso, ainda constam nos Parâmetros Curriculares Nacionais (PCN) e nas Diretrizes Curriculares Nacionais (DCN), e que embora sejam menos recentes ainda continuam em vigor. A Nota Técnica $n^{0} 32 / 2015$ destaca que essa ausência não exime as redes de ensino de seguirem as recomendações e normativas descritas nas DCN, e que qualquer restrição a essa abordagem estará em contradição com o que apontam as diretrizes.

Numa perspectiva histórica foi a emergência da epidemia de HIV/AIDS no final da década de 1980 e os casos de gravidez na adolescência, que aumentaram a demanda por trabalhos na área da saúde sexual e reprodutiva no contexto escolar. Entretanto, a literatura aponta que os/as professores/as se sentem despreparados/ as e com dificuldades para abordar os diversos aspectos da sexualidade descritos

2 A PEC 181 inviabiliza a questão do aborto no Brasil, tornando ilegal a interrupção da gravidez mesmo nos casos permitidos hoje por lei. 
no documento. No âmbito do ensino formal prevalece a perspectiva biológica da sexualidade, restrita, vinculada aos sistemas reprodutores masculino e feminino e às doenças relacionadas aos órgãos sexuais (CRUZ, 2008; FURLANI, 2008; VIANNA; UNBEHAUM, 2006; SILVA; MEGID NETO, 2006). A transversalidade igualmente não vem sendo desenvolvida, na medida em que $\mathrm{o}$ assunto tende a ser tratado apenas nas aulas de Ciências e Biologia (ALENCAR et al., 2008; JARDIM; BRÊTAS, 2006; ALTMANN, 2003; TONATTO; SAPIRO, 2002).

Frente à amplitude alcançada por essas questões e os limites de um enfoque que não contempla aspectos históricos e socioculturais da sexualidade, uma importante iniciativa do governo federal se refere ao desenvolvimento do curso de atualização Gênero e Diversidade na Escola (GDE) ${ }^{3}$, centrado na formação de professores/as do $6^{\circ}$ ao $9^{\circ}$ ano do Ensino Fundamental de diferentes campos disciplinares nas temáticas: gênero, sexualidade, orientação sexual e relações étnico-raciais (CARRARA et al., 2009; HEILBORN; ROHDEN, 2009). De acordo com os princípios do curso, não bastam leis ou normas para que os direitos humanos sejam assegurados, é necessário um trabalho de sensibilização das pessoas (PEREIRA, 2014).

Considerando a relevância dessa discussão, a presente pesquisa teve como objetivo analisar a influência do curso GDE na prática pedagógica de professores/as de Ciências do $6^{\circ}$ ao $9^{\circ}$ ano do Ensino Fundamental no Estado do Rio de Janeiro, em relação à abordagem dos temas sexualidade e gênero.

\section{Gênero e sexualidade: aspectos conceituais}

O movimento internacional de contracultura dos anos de 1960 e 70 trouxe o questionamento de muitos valores e padrões de comportamento. As reivindicações do movimento feminista, o surgimento da pílula anticoncepcional e suas consequências para a autonomia das mulheres, a liberação sexual, os avanços da medicina e o processo de laicização do Estado resultaram em profundas transformações sociais e culturais. $O$ conceito de gênero tem origem nesse contexto de luta do movimento feminista para conquista de direitos políticos e sociais das mulheres.

No âmbito acadêmico, o uso do termo gênero pelas pesquisadoras femi-

3 O curso GDE resulta da parceria entre a Secretaria Especial de Políticas para Mulheres (SPM), o British Council, Ministério da Educação, Secretaria Especial de Políticas de Promoção da Igualdade Racial e o Centro Latino Americano em Sexualidade e Direitos Humanos (CLAM) do Instituto de Medicina Social da UERJ. 
nistas resultou em formulações teóricas variadas no campo das Ciências Sociais e Humanas, centradas numa perspectiva crítica ao determinismo biológico na definição das diferenças sexuais. O conceito de gênero, embora apresente variações, tem em comum o foco na necessidade das mulheres serem consideradas como sujeitos históricos e ativos, em contraposição ao predomínio da concepção do homem como um ser humano universal (SCOTT, 1995).

A sexualidade, de igual modo, configura-se numa área simbólica e política, ativamente disputada, na qual diferentes grupos lutam para alterar modelos e ideologias sexuais. Inicialmente sob domínio religioso, o interesse pela regulação da sexualidade da população despertou a atenção do Estado, produzindo discursos reguladores que tomavam a sexualidade em função do funcionamento fisiológico ou de punções instintivas. A preocupação com a sexualidade entre médicos e profissionais reformadores morais do século XIX resultou na criação da disciplina sexologia, focada nas explicações dos fenômenos humanos em termos de causas internas e biológicas.

Os estudos de Foucault (2012) criticam essa tendência, ressaltando que a sexualidade não pode ser vista como um dado da natureza. $\mathrm{O}$ autor rejeita a hipótese repressiva da sexualidade - centrada na crença do controle social de uma energia natural incontrolável -, argumentando que a perspectiva essencialista ignora que a sexualidade é desenvolvida como parte de uma rede complexa de regulação social. Foucault denomina esse aparato de biopoder, uma força positiva preocupada com a administração e o cultivo da vida que não se expressa com base na proibição, mas sim na administração do que deve ser feito (WEEKS, 2010).

As evidências históricas e culturais sobre a ampla variação dos papéis de gênero contribuíram para crítica ao determinismo biológico e para a tentativa de separar sexualidade e gênero. $O$ que parecia um corpo naturalmente marcado pelo gênero era produto de uma persistente socialização com respeito aos padrões da época. Os estudos sobre a homossexualidade igualmente buscaram traçar a distinção entre o comportamento homossexual (considerado universal) e identidade homossexual, construída socialmente. De acordo com a perspectiva da construção social, a sexualidade é mediada por fatores históricos e culturais, concluindo que $o$ ato sexual não possui um significado social universal. A relação entre atos e os significados sexuais desses atos não é fixa, "as culturas geram categorias, esquemas e rótulos muito diferentes para estruturar as experiências sexuais e afetivas" (VANCE, 1995, p.17).

A necessidade de responder à epidemia de AIDS no final da década de 1980 fomentou o desenvolvimento de pesquisas sobre comportamento sexual entre diversos grupos populacionais, que salientaram a relevância do contexto social na compreensão das práticas sexuais e na definição das intervenções voltadas para a promoção da saúde entre os diferentes indivíduos e grupos sociais. Uma das 
importantes implicações dos estudos sobre a dimensão social do HIV se refere à maior conscientização da relação entre a sexualidade e as múltiplas formas de desigualdade e exclusão social, principalmente a pobreza, desigualdades de gênero e a discriminação étnica e racial (PARKER, 2009).

Nos últimos anos tem crescido a visibilidade de temas associados à diversidade sexual e de gênero nos meios de comunicação (novelas, noticiários, filmes e redes sociais), bem como na luta por direitos da população LGBTTI. A valorização da diversidade sexual e de gênero se contrapõe à ênfase nas convenções de gênero e nos padrões de heteronormatividade, caracterizada pelo caráter compulsório da heterossexualidade, articulado ao estabelecimento de uma ordem social na qual o homem deve seguir as convenções sociais de masculinidade e as mulheres de feminilidade (CARRARA et al., 2010).

Tal cenário revela a coexistência de diferentes visões que são disputadas no âmbito dos discursos e práticas de instituições e atores sociais (HENRIQUES, et al., 2007). Ilustra essa disputa os vetos de políticas educacionais associadas à sexualidade, ocorridos nos últimos anos, como por exemplo as proibições da distribuição do kit anti-homofobia para escolas da rede pública e do veto à divulgação de vídeos das campanhas de prevenção da AIDS entre jovens homossexuais; assim como a retirada da diretriz que propõe a superação das desigualdades educacionais, "com ênfase na promoção da igualdade racial, regional, de gênero e de orientação sexual" do Plano Nacional de Educação (PNE); dentre outros exemplos.

\section{Metodologia}

A pesquisa foi orientada pela abordagem metodológica qualitativa, caracterizada como um conjunto de práticas interpretativas utilizadas na intenção de compreender os significados que as pessoas atribuem aos fenômenos (DESLANDES; GOMES, 2007). A partir deste enfoque, foram realizadas entrevistas semiestruturadas com 12 professores/as da rede pública estadual do Rio de Janeiro sobre: perfil pessoal e profissional; práticas em sala de aula antes e após o curso GDE; motivações para fazer o curso; as contribuições do GDE para a prática profissional; e os desafios para a implementação de ações sobre sexualidade e gênero na escola.

Os/as professores/as entrevistados/as (2 homens e 10 mulheres) eram concluintes do curso GDE com idade variando de 26 a 59 anos e residentes em 
diferentes municípios (Rio de Janeiro, Valença, Volta Redonda, Nova Iguaçu, Cabo Frio, Itaboraí, Duque de Caxias e Macaé) do Estado do Rio de Janeiro. O perfil dos/as entrevistados/as quanto ao sexo coincide com o estudo realizado pelo INEP (CARVALHO, 2018) no qual as mulheres representam $81 \%$ do total de professores/as da Educação Básica do país.

Os dados coletados foram interpretados por meio da análise de conteúdo temática, caracterizada pela busca dos núcleos de sentido que compõem uma comunicação e que revelam o significado dos depoimentos (MINAYO, 2008). O processo envolveu a transcrição e leitura das 12 entrevistas, seguida da identificação das categorias de análise (referentes aos temas do estudo e aos núcleos de sentido) e interpretação dos significados do material categorizado, tendo por base as reflexões sobre aspectos históricos e socioculturais dos conceitos de gênero e sexualidade.

\section{Resultados e Discussão}

Frente ao objetivo de analisar os reflexos do curso GDE na prática pedagógica dos/as professores/as entrevistados/as, os depoimentos foram organizados nos seguintes tópicos: motivações e contribuições do curso para a prática educativa; barreiras e possibilidades de diálogos sobre sexualidade e gênero no contexto escolar após GDE; permanências e mudanças nas concepções de sexualidade e gênero; e perspectivas e desafios no ensino sobre sexualidade e gênero.

\section{Motivações e contribuições do curso para a prática educativa}

Dos/as 12 entrevistados/as, apenas três afirmaram que o tema sexualidade foi tratado na licenciatura, seja a partir dos sistemas reprodutores masculinos e femininos, seja como "conceito legitimado pela ciência" que não poderia ser contestado. Para os/as professores/as as diversas dimensões da sexualidade, discutidas no âmbito do curso GDE não foram contempladas nos cursos de graduação, principalmente na época que se formaram.

As motivações para realização do curso GDE foram: o desejo de aprender algo novo, a possibilidade de melhorar o currículo, a flexibilidade de ser um 
curso semipresencial ou em atenção à recomendação da Secretaria de Educação ou de Saúde do Município. Apenas duas professoras afirmaram ter procurado o curso por dificuldade em trabalhar temas relativos à sexualidade, principalmente, à homossexualidade; quatro afirmaram que já desenvolviam atividades sobre sexualidade no contexto escolar e buscaram o curso por interesse em se aprofundar no assunto. $\mathrm{O}$ fato do conteúdo de reprodução ser abordado na disciplina de Ciências Naturais possivelmente favorece a aproximação do/as professores/as de Ciências com o tema, quando comparado aos/as professores/ as de outras áreas disciplinares.

Foram citadas diversas contribuições do curso GDE tanto para a prática pedagógica, quanto para a vida privada. A perspectiva de construção social da sexualidade humana foi novidade para muitos/as. $\mathrm{O}$ acesso às diversas representações que envolvem a sexualidade humana colaborou para a compreensão de que várias das questões tomadas como naturais, como os estereótipos ligados ao gênero e à orientação sexual, e os padrões dos arranjos familiares, são construídos socialmente.

De um modo geral, o curso GDE provocou impactos e reflexões, de maior ou menor alcance, na vida dos/as profissionais. Todos/as admitem uma mudança de perspectiva em relação à sexualidade após a realização do curso, exemplificada pelos fragmentos das falas: "muda postura, a fala", "aprende a olhar o ser humano de maneira diferente", "a ter visão mais flexivel", "um outro olhar com relação aos alunos", "Uma visão mais ampla da sexualidade". A fala da Professora Fernanda ${ }^{4}$ reflete a influência do curso sobre a construção das identidades: "Não é um aprender pontual que eu vou aplicar no dia tal com a turma $X$, mas você muda muito sua postura e sua fala... É um aprimoramento para o professor no dia a dia". Igualmente foram citadas conquistas de ordem prática, como a maior facilidade em argumentar e compreender os/as alunos/as, a percepção de atitudes preconceituosas, sexistas e machistas dentro da escola e a percepção do próprio preconceito.

A aquisição de conhecimentos teóricos, principalmente sobre a homossexualidade, foi apontada como um dos pontos positivos do curso. Para parte do grupo, as discussões do curso foram incorporadas à vida cotidiana e promoveram mudanças nos discursos e práticas associadas às representações de gênero, bem como reflexões sobre visões e atitudes preconceituosas. Outros/as assinalaram que passaram a abordar ou se interessar pelo assunto apenas após a realização do curso.

4 Todos os nomes são fictícios. 


\section{Sexualidade e Gênero: barreiras e possibilidades de diálogos no contexto escolar}

Embora a percepção da desigualdade e o desejo de mudança estejam presentes na vida desses/as professores/as, foram relatadas situações relacionadas ao contexto social mais amplo, incluindo as relações pessoais, que apontam que as mudanças e reflexões estimuladas pelo curso GDE não dependem apenas de escolhas racionais e individuais. A fala da professora Sandra ilustra a falta de pares na escola: "É muito quantitativo de pessoas e discursos totalmente opostos ao seu, é uma luta de cem contra um".

Foram também relatadas algumas barreiras nas unidades de ensino para o desenvolvimento de atividades sobre sexualidade e para a aceitação dos direitos de cidadania, independente de orientação sexual, como por exemplo: não aprovação da direção da escola para implantar um projeto sobre sexualidade, restrições dos pais dos/das alunos/as à temática, não aceitação do uso do nome social entre alunos transexuais e travestis por parte dos/as professores/as e a postura conservadora de alguns alunos/as que se negam a discutir o tema homossexualidade em sala de aula.

Apesar das dificuldades foi observado que a maioria dos/as entrevistados/as se manteve engajada na tentativa de promover atitudes que valorizam a igualdade no dia a dia em sala de aula. Depreende-se que o curso contribuiu para desestabilizar padrões existentes e criar condições para que os/as professores/as repensassem suas visões, discursos e práticas associadas à sexualidade, questionando o senso comum e as construções sociais baseadas nas diferenças biológicas. Por exemplo, frente aos xingamentos e brincadeiras envolvendo aspectos sexuais, a Professora Ana afirma: "eu procuro ser bem espontânea com eles, de perguntar mesmo: Por que você tá passando a mão no outro? Tá apaixonado?" em outras situações de preconceito ela tem uma abordagem mais incisiva: "Uma vez uma aluno me perguntou: Professor Fulano é viado professora, é boiola?, E eu respondi: Ele já deu pra você? Primeiro, pra vocêfalar isso dele você tem que ter certeza, segundo, e qual o problema?". A professora Fernanda tem uma postura parecida, quando há algum xingamento em sala ela para a aula e inicia a discussão sobre os significados de palavrões, uma atitude que surpreende os/as alunos/as.

Sandra relatou o caso de um aluno homossexual que era assediado pelos outros garotos com toques nas partes íntimas e chamamentos do tipo: "Ô gostosa!" Segundo a professora, ele se sentia aceito e desejado pelo grupo, mas ela considerava uma agressão e um abuso. Um dia chamou o aluno para con- 
versar: "olha só, se você não fica chateado você deveria ficar, porque sem você perceber eles estão te desrespeitando". A partir desse caso ela desenvolveu o projeto final do curso do GDE5. Castro, Abramovay e Silva (2004) consideram essas "brincadeiras" como um tipo de violência e alertam para a naturalização dessas expressões, principalmente em ambiente escolar, em episódios nos quais a vítima comumente banaliza a situação e não percebe o ocorrido como algo negativo e intencional.

No conjunto de depoimentos dos/as professores/as constata-se um certo estranhamento à ideia de fluidez e instabilidade das identidades sexuais, presente nas expressões heteroflex ou bissexual, que apontam para processos de experimentação sexual para além da hetero e homossexualidade. Segundo Louro (2010), a dificuldade de compreender as propriedades de fluidez e inconstância da sexualidade são justificadas pela centralidade que ela adquiriu nas sociedades modernas, dado que a referência mais segura sobre os indivíduos diz respeito a sua identidade de gênero e sexual; o temor se refere à incerteza e ameaça de dissolução desse padrão a favor de uma identidade não fixa. Heilborn e Cabral (2006) consideram que a juventude deve ser entendida como um processo, formado por etapas sucessivas que vão, por meio das experiências, modulando a socialização dos/as jovens; esse período de experimentações não significa necessariamente que esses/as jovens terão suas "carreiras sexuais" estabilizadas em bissexuais ou "heteroflex", mas sim que estão gradativamente construindo suas trajetórias sexuais.

\section{Demais resistências e negociações}

Chama atenção o desacordo entre a visão dos/as professores/as após o curso GDE e o ponto de vista dos demais membros da escola. Segundo as professoras Carla e Ana, a escola aspira a um trabalho de orientação sexual voltado para a prevenção das DST/AIDS, da gravidez na adolescência e, principalmente, da prevenção das "sexualidades excêntricas", como o "problema das meninas afloradas' ou dos homossexuais na escola. As divergências de visões podem ser ilustradas pelos comentários jocosos ou apelidos. Ana recebeu o apelido de "a mulher da sexualidade, que anda com uma bolsa cheia de camisinhas" ou que "anda com uma prótese de pênis na cabeça e deixa cair camisinha por onde

5 No projeto final do GDE os/as cursistas deveriam desenvolver um projeto ou uma atividade para ser aplicada em sala de aula na Educação Básica, abordando os temas tratados durante o curso. 
passa". Já a professora Sandra ganhou o apelido de "defensora dos viadinhos". Elas declararam que essas "brincadeiras" acabam por desmotivar seu trabalho.

Imersos num cotidiano com precárias condições de trabalho, baixos salários e carga horária extensa, os/as professores/ concluintes do GDE buscam de alguma maneira aplicar em sala de aula o que aprenderam no curso. Mas, além desses entraves, enfrentam a falta apoio dos gestores (ex. direção), de outros professores/as e de parte dos/as alunos/as ou dos familiares. Ou seja, inserir o tema em sala de aula depende quase que exclusivamente da iniciativa e disposição do/a docente para enfrentar as adversidades. A ausência de apoio e de pares para amparar ou debater as situações vividas em sala de aula gera um sentimento de isolamento.

A falta de um diálogo acerca da diversidade sexual contribui para o silenciamento, invisibilidade e exclusão das pessoas que assumem padrões fora da matriz heterossexual, principalmente no ambiente escolar, reforçando valores heteronormativos (JUNQUEIRA, 2013). Para Butler (2010, p. 155), o imperativo heterossexual ao mesmo tempo em que possibilita certas identificações, impede ou nega outras, como é o caso da homossexualidade. E s s a matriz excludente exige a produção de "seres abjetos", ou seja, "aqueles que ainda não são sujeitos, mas que formam o exterior constitutivo relativamente ao domínio do sujeito". O sentimento de identificação e desprezo exibido pelos meninos, ilustrado pelas trocas de olhares e comentários, são formas de fazer emergir a norma heterossexual, ou seja, para que o padrão apareça e sobressaia é necessário apontar o que está fora deste padrão. Segundo a autora, a "valência da abjeção" (p. 156) se configura como uma iminência ameaçadora; o que ajuda a entender porque tal comportamento é mais comum entre os garotos do que entre as meninas, como já descrito por Borges et al. (2011). As meninas, além de não se sentirem ameaçadas em suas identidades, encontram-se em posição de inferioridade, considerando que a homofobia se imbrica com a desvalorização do feminino e com isso pode haver certa identificação das meninas com o preconceito sofrido por homossexuais.

No conjunto de depoimentos, a religião também foi citada como um dos fatores que interfere no diálogo aberto sobre a diversidade sexual, chegando algumas vezes a intimidar o/a professor/a a prosseguir na abordagem do tema. A Professora Sandra, embora admita que o tema seja muito delicado, faz uma abordagem gradativa, respeitando a religião do/a aluno/a, e sem imposição de uma única "verdade". Em sua opinião, compreender as diferenças é um processo complexo no sentido de rejeitar os próprios valores e no reconhecimento do que é diferente. Outro entrave diz respeito ao preconceito em relação a diversidade religiosa, como assinalado pela Professora Fernanda, praticante da umbanda. De acordo com a professora, os símbolos do catolicismo podem ser exibidos 
com orgulho, já os símbolos relacionados às religiões africanas são estigmatizados. Ela chama a atenção para a hegemonia dos costumes cristãos versus o preconceito com outras expressões religiosas e reflete sobre a diferença dialógica entre aceitar e respeitar as diferenças. A indignação da professora com a ideia de 'aceitação' está ligada a suportar uma situação/evento que não seja o ideal, o que para ela não é suficiente. De acordo com os pressupostos do curso GDE (CARRARA et al., 2009), "aceitar o outro" significaria um gesto de 'bondade', 'paciência' com o suposto grupo inferior, desviante da norma. E apenas aceitar não basta, é fundamental o reconhecimento ao respeito dos valores culturais dos diferentes grupos sem qualquer ameaça à dignidade humana. Embora o curso GDE reforce o respeito à diversidade, seja ela de gênero, sexual, raça/etnia e religiosa, a professora Fernanda considera que o curso não forneceu elementos suficientes para auxiliar na discussão sobre o respeito à diversidade religiosa.

\section{Concepções sobre (homo)sexualidade e gênero: permanências e mudanças}

O grupo entrevistado considera importante discutir sobre sexualidade com os/as alunos/as, contudo não há um consenso se falar sobre sexualidade possa induzir à iniciação sexual precoce. Para alguns/as professores/as as aulas de sexualidade tem como objetivo tirar dúvidas, orientar e prevenir a gravidez e as DST e ampliar a capacidade de escolha dos/as alunos/as. Na perspectiva desse grupo, o conhecimento 'cientificamente comprovado' oferece mais clareza, podendo adiar a entrada na sexualidade.

No entanto, a professora Sheila tem receio de abordar a sexualidade de forma tão natural: "Mas isso é um receio que eu tenho de que aí, por a gente falar de forma tão natural, e dizer que, 'ah, mas é legal mesmo e não sei o que', eu acho que isso pode também induzir". Em outro trecho da entrevista revela que tem dúvidas se a distribuição do kit anti-homofobia pode incitar a homossexualidade entre os/as alunos/as ao presumir que o mesmo trata a homossexualidade como natural e prazerosa: "É porque se eu falo, 'ah é natural, e não sei o que, é prazeroso, é gostoso', pode criar sim no adolescente a vontade de experimentar, a mesma coisa aqui é o kit gay".

Compreendendo esse terreno como um campo de disputas, os/as professores/as foram questionados acerca das causas da homossexualidade. Os relatos foram variados e houve dificuldades para responder a questão. Dos doze relatos, quatro professores/as ofereceram explicações estritamente biológicas, como a 
genética ou ação hormonal ao longo da vida, como sendo causa da homossexualidade. Entre os/as demais há uma tendência em considerar a ausência de uma causa específica ou explicação conclusiva para a homossexualidade e uma disposição em refletir sobre o tema.

Com relação aos direitos civis todos/as os/as entrevistados/as se declararam a favor da igualdade de direitos civis independente da orientação sexual, tendo por base o argumento da igualdade de direitos e deveres a todos/as. Esse discurso "politicamente correto" é contrastado com as várias ressalvas feitas por alguns/ as entrevistados/as quanto ao casamento religioso, bem como a adoção de filhos. A resistência à igualdade de direitos é corroborada pela Professora Lúcia, numa associação inalterável entre casamento e reprodução: "Porque eu acho que dois homens não são um casal e duas mulheres não são um casal. Eu sou a favor assim, por exemplo, na parte da herança (...). Agora, a perpetuação da espécie depende de reprodução e não existe isso em um casamento homossexual".

A adoção de crianças por casais homossexuais é ainda mais polêmica. Parece ser um limite dentro da perspectiva de igualdade de direitos, tão defendida por esses/as professores/as. Nesse caso, justifica-se a impossibilidade da adoção não pela falta de condições do casal, mas sim pela preocupação em preservar a integridade da criança, dados corroborados pela pesquisa de Dinis e Cavalcanti (2008).

É importante destacar que durante as entrevistas apareceram diversas articulações entre as categorias de gênero, raça, sexualidade e classe social. Fica claro que para os/as professores/as existe uma compreensão do que seria um modelo ideal de indivíduo e quem não se enquadra nesse modelo passa a ser vítima de preconceito: "O que venderam pra gente, como perfeito, como correto, é o homem branco, hetero, nivel de escolaridade é nível superior; e esse é o padrão que a sociedade escolheu" Professora Mara.

De um modo geral todos/as os entrevistados/as concordam que há diferenças entre o que se espera de uma moça ou rapaz no que diz respeito a passagem à sexualidade. Na perspectiva dos/as entrevistados/as nos últimos anos houve mudanças em relação a essa expectativa, porém ainda são exigidos determinados modelos de comportamento sexual e social para cada um dos sexos. Carrara et al. (2009) esclarecem que há modelos de gênero rigidamente estabelecidos que imprimem práticas e representações específicas para rapazes e moças e qualquer desvio pode ocasionar duras críticas ou discriminações sociais. A preocupação em tentar desfazer esses estereótipos de gênero fica clara na fala da Professora Julia. A partir da realização do curso GDE ela conseguiu compreender que algumas características tidas como inatas são socialmente construídas, e diz que se policia constantemente para evitar atitudes preconceituosas. 


\section{Perspectivas e desafios no ensino sobre sexualidade e gênero}

Todos/as entrevistados/as concordam que é preciso desenvolver atividades sobre gênero no espaço escolar, porém destacam a importância da família na socialização dos/as filhos. De acordo com Heilborn (2004), a família ainda ocupa um lugar chave na socialização das novas gerações no que diz respeito ao sexo. Nesse aspecto, a Professora Sandra explica a dificuldade da escola em competir com as normas e valores construídos na vida familiar: "eu acho que é muito complicado você querer entrar em uma estrutura familiar consolidada nesse papel, que têm disso, o pai manda e a mãe obedece e cuida dos filhos".

Para os/as professores/as, a escola desenvolve poucas atividades que estimulam a reflexão das diferenças de gênero. Porém, foram descritas ações e esforços individuais para superar os estereótipos e as desigualdades de gênero que visam diferenciar o que é natural do que é socialmente construído, como ilustrado pelo relato da professora Mara: "eu gosto de trabalhar com eles o que é cultural e o que é natural, pra mostrar que o que é cultural a gente consegue mexer".

A professora Sandra, corroborando coma literatura (ROSISTOLATO, 2009; ALMEIDA et al., 2011), relatou circunstâncias de contradição entre o âmbito público (profissional) e privado (esfera familiar). Parte dos/as professores/as declara que a divisão de tarefas já faz parte de seus relacionamentos pessoais, mas, no geral, são relatadas assimetrias de gênero na esfera familiar e doméstica. Eles/as reconhecem que as mulheres ainda estão sujeitas a uma dupla jornada de trabalho e há um sentimento de culpa por não dedicarem tanta atenção aos filhos. Ou seja, houve avanços, mas a identidade das mulheres continua atrelada ao universo doméstico, aos cuidados e à maternidade (MARCONDES et al., 2003, p.93).

Nos relatos dos/as professores/as acerca dos comportamentos dos/as alunos/as, foi possível identificar uma clara divisão entre atributos associados aos homens e atributos associados às mulheres. Foi citado, de forma recorrente, que as meninas amadurecem sexualmente antes dos meninos e são mais quietas e comportadas, quando comparadas aos homens da mesma faixa etária. Uma das razões apontadas pelos/as entrevistados/as para essas diferenças diz respeito ao aprendizado dos papeis de gênero no ambiente familiar e na sociedade em geral. No entanto, segundo a professora Ester, tem havido uma inversão de papeis tradicionais de gênero entre suas alunas do Ensino Médio, principalmente pelo comportamento e vestuário, que não são fáceis de serem compreendidas: "Eu vejo mais as meninas dando mais em cima dos meninos do que os meninos 
dando em cima das meninas. (...) na minha época de escola a coisa era diferente, a coisa era mais fechada, mais trancada, existia uma outra magia..." (Ester).

De acordo com Giddens (1993), as mudanças sexuais ocorridas entre as moças foram muito mais pronunciadas do que entre os rapazes o que talvez possa ajudar a explicar o estranhamento da professora Ester. O que mudou radicalmente entre as gerações foi a atitude de muitas adolescentes com relação a anuência de se envolver na atividade sexual, o que não exclui (embora em certo grau) a presença da distinção entre garota decente ou vadia, e a exibição das conquistas masculinas. As mudanças e permanências associadas ao gênero ao longo da história recente remetem para a pertinência de se promover uma reflexão entre os/as docentes sobre o tema, assinalando as conquistas e barreiras associadas à ocupação nos espaços públicos e privados, às diferenças salariais $\mathrm{e}$ às tensões presentes nas relações entre homens e mulheres.

Demais professores/as, por sua vez, tentam desconstruir os estereótipos de gênero por meio de dinâmicas ou atividades já nas primeiras séries do Ensino Fundamental. Mara, por exemplo, durante a 'rodinha' ${ }^{6}$ do $2^{\circ}$ ano do Ensino Fundamental orienta sempre que os/as alunos/as se misturem, já que as meninas tendem a se agrupar de um lado e meninos de outro.

A mesma professora faz questão de não associar as cores ao sexo, estimulando que meninos e meninas desenhem em folhas rosas, azuis ou brancas, aleatoriamente; também estimula que os/as alunos reflitam sobre atitudes consideradas femininas ou masculinas. No entanto, Mara considera que a descontinuidade do trabalho por parte dos/as outros/as docentes prejudica o trabalho de desconstrução realizado anteriormente: Porque não adianta nada eu ter uma postura com meu aluno se o outro professor não tem a mesma postura. Dele falar: 'isso não é coisa de menino', 'isso não é coisa de menina', e aí eu tô tendo o maior trabalhão e no dia de fazer o cartãozinho dá a folha rosa pra menina e a azul pro menino.

Tal relato destaca a importância do curso GDE ser acessível aos/às demais servidores/as da instituição escolar, incluindo gestores, serventes e merendeiras, cada qual com níveis diferentes de complexidade, para que a discussão seja integrada e permanente na escola. Até o momento não há relatos de pesquisas sobre o repasse do conteúdo do curso GDE aos demais profissionais da escola, contudo esse pode ser um fator motivador e que auxilie no desenvolvimento das ações.

6 A hora da rodinha é o momento em que as crianças se sentam no chão, em círculo juntamente com a professora. É um momento em que as crianças podem se expressar livremente e são convidadas a refletir sobre determinado assunto. 


\section{Considerações Finais}

A gravidade das situações de discriminação por gênero e orientação sexual pode ser atestada por estatísticas recentes que apontam que apenas no ano de 2017 foram registrados 445 casos de assassinato por homofobia (GGB, 2018); e que a cada duas horas doze mulheres são assassinadas no Brasil (LIMA et al., 2017). Embora ainda encontre resistência por parte de alguns setores da sociedade, o enfrentamento dos processos de discriminação envolvendo gênero e orientação sexual vem crescendo a fim de garantir a igualdade de direitos a todos os indivíduos, independente de cor, sexo, raça/etnia ou orientação sexual.

As iniciativas voltadas para abordagem da diversidade sexual no contexto da rede pública de ensino representam um desafio frente aos diferentes valores e normas morais, culturais, religiosas e familiares que permeiam os temas gênero e sexualidade, como ilustram os avanços e recuos que ainda se fazem presentes na segunda década do século XXI. Como indicado, essa tensão é resultado de forças conservadoras diante de conquistas no plano dos direitos humanos, sexuais e reprodutivos. A pressão exercida por esses grupos tem impacto nas políticas públicas, especialmente na área da Saúde e da Educação voltadas para as ações de igualdade independente da orientação sexual e ao combate à epidemia de AIDS, que avança entre a população jovem, principalmente com práticas homossexuais.

A perspectiva histórica e sociocultural da sexualidade e do gênero vem ganhando visibilidade nos meios acadêmicos, mas a sensibilização das pessoas não se efetiva num curto período. É necessária uma proposta permanente de discussão dos temas no ensino formal, sinalizando para que os cursos superiores, principalmente as licenciaturas, incluam em seus currículos essas questões. Como apontam os achados apresentados, talvez em virtude da transversalidade do tema, este acaba sendo menos valorizado do que os demais conteúdos dos currículos, e em alguns casos não é incluído. Da mesma forma, há a necessidade de formação continuada para profissionais da educação, incluindo gestores e pessoal de apoio que lidam diretamente com crianças e adolescentes, além de iniciativas de consolidação das ações dentro das instituições escolares.

Tendo em vista a importância de políticas que promovam o debate no campo do gênero e da sexualidade, espera-se que esse trabalho contribua para uma reflexão mais profunda acerca das dificuldades e limitações de concretização de uma política pública e de como os/as professores/as assumem a responsabilidade como agentes da transformação de mentalidades e práticas. Almeja-se que essa reflexão fomente a divulgação de pesquisas no Ensino de Ciências e Educação, e contribua para a consolidação dessa área de investigação. 


\section{REFERÊNCIAS}

ALENCAR, R. A. et al. Desenvolvimento de uma proposta de educação sexual para adolescentes. Ciência \& Educação, v.14, n.1, p. 159-168, 2008.

ALMEIDA, S. A. et al. Orientação sexual nas escolas: fato ou anseio? Rev Gaúcha Enferm., v.32, n.1, p. 107-113, mar. 2011.

ALTMANN, H. Orientação sexual em uma escola: recortes de corpos e de gênero. Cadernos Pagu, n.21, p.281-315, 2003.

BORGES, Z. N. et al. Percepções de professoras de ensino médio e fundamental sobre a homofobia na escola em Santa Maria (Rio Grande do Sul/Brasil). Educar em Revista, Curitiba, Brasil, n.39, p.21-38, jan./abr. 2011.

BUTLER, J. Corpos que pesam: sobre os limites discursivos do "sexo". In: LOURO, G. L. O corpo educado: pedagogias da sexualidade. 3. ed. Belo Horizonte: Autêntica Editora, 2010. p.151-172.

CARRARA, S. et al. (Orgs.). Gênero e diversidade na Escola: Formação de Professores/ as em Gênero, Orientação sexual e Relações étnico-raciais. Livro de conteúdo. Rio de Janeiro: CEPESC; Brasília: SPM, 2009.

CARRARA, S. et al. (Orgs.). Curso de Especialização em Gênero e Sexualidade. v.3, Rio de Janeiro: CEPESC; Brasília, DF: Secretaria de Políticas Públicas para Mulheres, 2010.

CARVALHO, M. R. V. Perfil do professor da educação básica. Brasília, DF: Instituto Nacional de Estudos e Pesquisas Educacionais Anísio Teixeira, 2018. 67 p.

CASTRO, M. G.; ABRAMOVAY, M.; SILVA, L. B. Juventudes e sexualidade. Unesco. Brasília, agosto, 2004.

CRUZ, I. S. Percepções de professoras de Ciências sobre gênero e sexualidade e suas implicações no Ensino de Ciências e práticas de educação sexual. In: FAZENDO GÊNERO, 8. 2008, Florianópolis. 2008. Anais... Florianópolis: EdUFSC, 2008.

DESLANDES, S. F.; GOMES, R. A pesquisa qualitativa nos serviços de saúde - Notas teóricas. IN: BOSI, M. L. M.; MERCADO, F. J. Pesquisa qualitativa de serviços de saúde. 2.ed. Petrópolis, RJ: Vozes, 2007. p. 99-120.

DINIS, N. F.; CAVALCANTI, R. F. Discursos sobre homossexualidade e gênero na formação em pedagogia. Pro-Posições, v.19, n.2(56), p.99-109, maio/ago. 2008.

FOUCAULT, M. (1988). História da sexualidade 1: A vontade de saber. 22a impressão. Rio de Janeiro: Edições Graal, 2012.

FURLANI, J. Mulheres só fazem amor com homens? A educação sexual e os relacionamentos entre pessoas do mesmo sexo. Pró-Posições, v.19, n.2(56), p.111-131, maio-ago, 2008. 
GGB - Grupo gay da Bahia. Pessoas LGBT mortas no Brasil. Mortes violentas de LGBT no Brasil. Relatório 2017. Disponível em: https://homofobiamata.files.wordpress. com/2017/12/relatorio-2081.pdf Acesso em: 08 set. 2018.

GIDDENS, A. A transformação da intimidade - sexualidade, amor e erotismo nas sociedades modernas. São Paulo: Editora da Universidade Estadual Paulista, 1993.

HEILBORN, M. L. Família e sexualidade: novas configurações. In: HEILBORN, M. L. (Org.). Família e sexualidade. Rio de Janeiro: Editora FGV. 2004. p. 9-14.

HEILBORN, M. L.; CABRAL, C. S. As trajetórias homo-bissexuais. In: HEILBORN et al. (Orgs.). O aprendizado da sexualidade: reprodução e trajetórias sociais de jovens brasileiros. Rio de Janeiro: Garamond e Fiocruz, 2006. p.361-397.

HEILBORN, M. L.; ROHDEN, F. Gênero e diversidade na escola: a ampliação de um debate. In: CARRARA et al. (Orgs.) Gênero e diversidade na escola: formação de professoras/ES em gênero, sexualidade, orientação sexual e relações étnico-raciais. Livro de conteúdo. Rio de Janeiro: CEPESC; Brasília: SPM, 2009. p.11-12.

HENRIQUES, R. et al. (Org.). Gênero e Diversidade Sexual na Escola: reconhecer diferenças e superar preconceitos. Cadernos SECAD, n. 4, Brasília, maio, 2007.

JARDIM, D. P.; BRÊTAS, J. R. S. Orientação sexual na escola: a concepção dos professores de Jandira - SP. Rev. Bras. Enferm. v.59, n.2, p.157-162, mar-abr, 2006.

JUNQUEIRA, R. D. “Temos um problema em minha escola: um garoto afeminado demais." Vigilância de gênero, heteronormatividade e heterossexismo no cotidiano escolar: notas sobre a pedagogia do armário. In: MAIO, E. R.; CORREA, C. M. A. (Orgs.). Gênero direitos e diversidade sexual: Trajetórias escolares. Maringá: UEM, 2013. p.191-207

LIMA, R. S. et al. Anuário Brasileiro De Segurança Pública. Fórum Brasileiro de Segurança Pública. Ano 11. 2017 Disponível em: < http://www.forumseguranca.org. br/wp-content/uploads/2017/12/ANUARIO_11_2017.pdf . Acesso em: 07 set. 2018.

LOURO, G. L. Pedagogias da Sexualidade. In: LOURO et al., (Orgs.). O corpo educado: Pedagogias da sexualidade. 3.ed. Belo Horizonte: Autêntica, 2010. p. 7-34.

MARCONDES, W. B. et al. O peso do trabalho "leve" feminino à saúde. São Paulo em Perspectiva, v. 17, n. 2, p. 91-101, 2003.

MINAYO, M. C. S. O desafio do conhecimento: pesquisa qualitativa em saúde. São Paulo: Hucitec, 2008.

MIRANDA, C. M.; SANTOS, A. P. Lute como uma menina: questões de gênero nas ocupações das escolas de São Paulo em 2016. Revista Observatório, v. 3, p. 417-444, 2017.

MOURA, F. P. "Escola Sem Partido": relações entre Estado, educação e religião e os impactos no ensino de história. 189 f. Dissertação - (Mestrado Profissional em Ensino de História) Instituto de História, Universidade Federal do Rio de Janeiro, Rio de Janeiro, 2016. 
PARKER, R. Unintended consequences: evaluating the impact of HIV and AIDS on sexuality research and policy debates. Cad. Saúde Pública, v.25 Sup, p.251-258, 2009.

PEREIRA, Z. M. Sexualidade e Gênero na Pesquisa e na Prática de Ensino em Biociências e Saúde. 2014. 201f. Tese (Doutorado em Ensino em Biociências e Saúde) - Programa de Pós-Graduação em Ensino em Biociências e Saúde, Instituto Oswaldo Cruz, FIOCRUZ, Rio de Janeiro, 2014.

ROSISTOLATO, R. P. R. Gênero e cotidiano escolar: dilemas e perspectivas da intervenção escolar na socialização afetivo-sexual dos adolescentes. Estudos Feministas, v. 17, n. 1, p. 11-30, 2009.

SCOTT, J. Gênero: uma categoria útil de análise histórica. Educação \& Realidade, v. 20, n.2, p. 71-99, jul-dez, 1995.

SEFFNER, F; BORRILLO, D.; RIBEIRO, F. B. Gênero e sexualidade: entre a explosão do pluralismo e os embates da normalização. Civitas (Porto Alegre), v. 18, p. 5-9, 2018.

SILVA, R. C. P.; MEGID NETO, J. Formação de professores e educadores para a abordagem da educação sexual na escola: o que mostram as pesquisas. Ciência e Educação, v.12, n.2, p.185-197, 2006.

TONATTO, S.; SAPIRO, C. M. Os novos Parâmetros Curriculares das Escolas Brasileiras e Educação Sexual: uma proposta de intervenção em Ciências. Psicologia \& Sociedade, v.14, n.2, p.163-175, jul./dez, 2002.

VANCE, C. A antropologia redescobre a sexualidade: um comentário teórico. PhysisRevista de Saúde Coletiva. v.5, n.1, p. 7-32, 1995.

VIANNA, C.; UNBEHAUM, S. Gênero na Educação Básica: Quem se importa? Uma análise de documentos de políticas públicas no Brasil. Educ. Soc., v. 27, n. 95, p.407428, maio/ago. 2006.

WEEKS, J. O corpo e a sexualidade. In: LOURO, Guacira Lopes. O corpo educado: pedagogias da sexualidade. 3. ed. Belo Horizonte: Autêntica Editora, 2010. p. 35-82.

Texto recebido em 08 de setembro de 2018.

Texto aprovado em 29 de novembro de 2018. 